\title{
Developing a Modern Mythology for Alzheimer's Disease
}

\author{
Mario D Garrett* \\ San Diego State University, USA
}

*Corresponding author: Mario D Garrett, School of Social Work, San Diego State University, USA.

Received Date: June 20, 2019

Published Date: June 26, 2019

\section{Introduction}

When Alois Alzheimer identified plaques and tangles in the brain of 45-year-old Auguste Deter as the possible cause of her dementia this observation quickly became enshrined as a new disease: Alzheimer's disease. Today Alzheimer's disease attracts the third most funded research in the National Institutes of Health (NIH) [1]. while in contrast Auguste Deter died a painful death from infection from bedsores, an easily preventable disease. Still today, while investing in research on Alzheimer's disease we are overlooking the need for palliative care and enhancing the wellbeing of the individual living with dementia. In an 18-month study [2] where half of the 323 nursing home patients living with dementia died, most died of eating problems (86\%), followed by high fever (53\%) and pneumonia (41\%). While dying they expressed shortness of breath $(46 \%)$ and pain (39\%). In their last 3 months of life nearly half $(41 \%)$ of these patients underwent an invasive intervention (hospitalization, emergency room visit, parenteral therapy, or tube feeding) [2]. Caregivers still rarely link palliative care to dementia [3]. While concentrating on finding a cure we are ignoring the person living with dementia. Understanding the dominance of this intervention/cure approach in contrast to a more palliative/ wellbeing approach requires a broader investigation of Alzheimer's disease history and how the disease has become a political as well as an economic commodity.

Dementia is an umbrella or superordinate category that encompasses many types of specific brain diseases that include Alzheimer's disease and are likely to have multiple causes and different paths of progression, most remain unknown [4]. After a century of studying Alzheimer's disease an overall understanding of the disease eludes researchers [5]. Appreciating that the search for a cure cannot be achieved without understanding its true cause, our current approach relies on myths to replace this void in our understanding. These myths are: that a simple biological mechanism causes Alzheimer's disease; that everyone will eventually get the disease; that the prevalence of the disease will stress our health care system; and that a cure is imminent. All these myths point to one option only, to find a cure.

Although these myths are related, by distinguishing them it will make the task of highlighting specific inaccuracies more manageable. While acknowledging that the aim for a cure is commendable, in the interim millions of people living with Alzheimer's disease and their caregivers and family, remain without effective management of the disease. Since research relies on funding an essential element is garnering public support by providing simplified stories with a clear narrative. In Alzheimer's disease research this has developed into myth in order to allow researchers to conduct their work while gaining public support and public funds. But after repeated scientific failures, this mode of communication is untenable. Scientists remain perplexed by Alzheimer's disease while the general population has become increasingly fearful of it. Although scientists appreciate the complexity of the disease, the public myth has had broader negative consequences. The public believes Alzheimer's disease to be random while similarly clinicians are resigned to the futility of intervention.

Scientifically, the methodology for studying Alzheimer's disease requires a framework that establishes clinical parameters that impact the disease how they interact with each other and within the environment. Instead what we have is a piecemeal framework promoted by the U.S. National Institute on Aging (NIA) that focuses on very specific simplified biological attributes of this process $[6,7]$. Such "Myths of science are unquestionably seductive...But they are misleading" [8]. Whether as a simplified story [8] or as "explanatory models" [9] scientific myths ultimately provide a 
false belief [10] and act more as a religious and fictional metaphors rather than as science $[11,12]$. Because myths help simplify very complex phenomena, myths are unavoidable. We can modify myths but not eliminate them.

\section{Biological Myth}

Even after investing enormous resources over the last forty years to find a cure for Alzheimer's disease-and providing one of the main impetus in 1976 for the establishment-we are not much closer to finding a cure. We still lack any semblance of how the disease can be stopped, let alone cured [13-15]. As a result research remains disorganized, clinicians continue to be confused, and the public is becoming increasingly worried [16,17]. As a singular disease Alzheimer's disease has already been compared to a myth [18]. Although there are many potential alternate approaches to developing research guidelines on Alzheimer's disease [19-24] in 2018 the NIA relapsed back to the original biological definition of a century ago, but this time discounting the clinical expression of the disease [6]. In mental health history, for the first time the clinical aspect of the disease-how it is expressed through loss of memory, changes in mental capacities and mood and personality changeswill be ignored in exclusive preference to its biological correlates [6]. This Research Framework has developed its own myth about Alzheimer's disease.

In contrast to the earlier 2011 guidelines [7] Alzheimer's disease is being defined by plaques and tangles (A and $\mathrm{T}$ ) while overall neurological damage $(\mathrm{N})$ defines severity. By ignoring how the disease is expressed, the myth establishes that the disease is exclusively caused by two misfolded proteins:

\section{Biological Myth}

Two proteins mis-fold and accumulate in the brain, interfering with the neurochemical mechanisms, resulting in accumulated damage to the brain that leads to death. Even if individuals do not manifest it, the disease is likely already present.

That the biology contributes to and is part of the process of Alzheimer's disease is universally accepted. The myth emerges when there is no established criterion of how much the biology contributes to the disease. Because universal standards on biomarkers density and cutoff points "...have not yet been established" [6, p.551] any presence of these AT(N) is an indication of Alzheimer's disease. The presence of inconsistencies expose it for what it is, a myth. Such inconsistencies are reflected in unexpectedly high false positives and high false negatives-mis-identifying those adults with Alzheimer's disease and wrongly identifying unimpaired individuals with Alzheimer's disease. "Up to $60 \%$ of CU [cognitive unimpaired] individuals over age 80 years have AD [Alzheimer's disease] neuropathologic changes at autopsy or by biomarkers...Thus, using a clinical diagnosis of 'AD' to ascertain absence of disease is associated with an error rate exceeding $50 \%$ in the elderly." 6 p.552]. And then there are false negatives, where the majority of people with Alzheimer's disease do not have any of the biomarkers, so that '...using a clinical diagnosis of 'AD' to ascertain absence of disease is associated with an error rate exceeding $50 \%$ in the elderly."[6, p. 552]. Although some diagnostic procedures in medicine cannot avoid some false positives and false negatives, the high rate of the new Framework with around 50\% is however uncharacteristically high, similar to a coin toss and falls short of scientific methodological standards.

\section{Political Myth}

Alois Alzheimer's original observations of plaques and tangles were treated as unremarkable at the time [25]. There were earlier observations, especially by Oskar Fischer who had also been discussing a variant of dementia that afflicts younger people under the synonymous term presbyophrenia. Over the next two decades, presbyophrenia was commonly used in the literature, before it disappeared suddenly in favor of Alzheimer's disease in 1955 [26]. Alzheimer argued that the tangles are independently important and Fischer assumed that the tangles came as a result of plaque growth. The 2018 NIA-AA Framework now sides with Fischer [6], but with rising nationalism in 1920 Germany, the ideas by the Jewish Fischer were unlikely to be promoted. Despite earning no support from Alzheimer's colleagues that the new Alzheimer's disease was different from late-onset senile dementia, Emil KraepelinAlzheimer's supervisor at the Munich clinic-included “Alzheimer's disease" as a new unique disease in the eighth edition of his 1910 book Psychiatre. This was a political move to counteract the great strides made by their nemesis clinic in Prague directed by Arnold Pick and where Fisher worked [27].

Fast forward in time, the second political event that falsely promoted the uniqueness of this disease came about with the creation of the NIA, with Robert Butler appointed as its first director in 1976. Despite Butler's interest in social inequity he confessed that: "I decided that we had to make it [Alzheimer's disease] a household word...And I call it the health politics of anguish."[28]. In response, and playing the "health politics of anguish," the founders of the NIA ingeniously focused on Alzheimer's disease as a specific disease. Thanks to Emil Kraepelin, Alzheimer's disease could be considered a biomedical disease - a real disease - and not just a condition of old age (senility) [27].

Now, the fate of Alzheimer's disease became inextricably woven with the promotion of the NIA. The founding members of the NIA knew that they needed constituents to bring their mission to the attention of Congress. They also needed to persuade the public that Alzheimer's disease research was not only a national priority, but that it was their priority as well. This strategy involved promoting locally based Alzheimer's Associations. Such grass-root lobbying was essential to bringing public pressure on local and national representatives to support NIA's mission [28]. The strategy built on the myth that unless we can cure Alzheimer's disease then we will be faced with a cataclysmic accumulation of people living with dementia whom we cannot care for. The political myth can be phrased as follows:

\section{Political Myth}

Unless we find a cure, Alzheimer's disease is going to overrun the health care system. 
In contradiction to this myth, older people will inevitably die, even if Alzheimer's disease is eradicated, most likely after a protracted period of illness. If we eliminate the top diseases of older adults, such as cancer, diabetes, cardiovascular disease, stroke, influenza, pneumonia, and chronic obstructive lung disease there will be only a small extension of life [29]. It seems counterintuitive but eliminating one disease could even result in longer life with more disability. Most older adults suffer from not just one, but multiple health conditions in later life. Assuming that we can cure one disease, say cancer, we will still face-sooner rather than later-another terminal disease, or the same disease stronger or in a different part of the body. Some diseases kill us slower, so while extending our life we might acquire increased disability. Statistically researchers can eliminate specific killer diseases and then predict life expectancy and disability. In one study [30] by eliminating cancer the researchers predicted that one fifth of the years of life gained would be spent in poor health and increased cost. On the other hand, eliminating musculoskeletal conditions would result in an additional year of good health for women and under half a year for men [31]. In contrast, eliminating cardiovascular disease and cancer will increase life expectancy but with increased periods of illness. While eliminating mental conditions (including depression and suicide) will increase life together with reduced periods of illness [30]. By eliminating all killer illnesses, we expect to see a 10 to 11-year improvement in overall life expectancy at birth, increasing the theoretical limit to life expectancy in 2016 to 96 years [29]. But we will still die.

The question to ask therefore is not to eliminate all diseases, since for older adults there will always be a terminal disease waiting but to provide palliate care for those we cannot cure. The Political Myth is making the wrong assumption by focusing on a disease that consuming health care services. The aging of population, by itselfwith or without dementia-will place increasing pressure on the health care system as a result of increasing prevalence of chronic diseases. Other diseases (e.g. ESRD) are much more expensive, last longer and their prevalence is increasing just as fast [32]. Singling out one disease in order to reduce health care utilization is as logical as applauding suicide for accomplishing this same objective.

\section{Pharmaceutical Myth}

Among all the different types of dementias, Alzheimer's disease occupies a prominent role in research. Coming as the third most funded research topic across all of the U.S. National Institutes of Health and number one at the NIA [1]. Although Alzheimer's disease mainly afflicts older adults, the disease was initially diagnosed in younger people. Because of ageism it was only when Alzheimer's disease became a young person's disease did the disease gain prominence [33]. Now a diagnosis of Alzheimer's disease is advertised as a death knell [34] and finding a cure has been promoted as the only solution [1].

The biopharmaceutical companies have a perfect failure rate in finding a cure. However, by repositioning drugs-applying existing drugs that were developed for other diseases-easier profits can be achieved since no research and development costs are involved [35]. Mathematical models-rather than scientific experiments and clinical trials-select drugs for Alzheimer's, Parkinson's and multiple sclerosis [36]. Such practices might be good business, but they are of little scientific value. Results of trials that prove unsuccessful are stopped and contribute little, if anything, to our scientific knowledge. The pharmaceutical industry hopestogether with the public-that an effective drug will eclipse the scientific question of the mechanism of action of the drug. Scientific questions that relate to whether the drug works because of its chemical structure, mechanism of action, or similar pharmacological effects (known as "drugs class effects"), or because of having a less stringent outcome (referred to as "surrogate endpoints in trials") will remain uncertain [37]. Repositioning has so far been an economic rather than a scientific strategy, but it lulls the public into this idea that eventually they will find a drug that works, the pharmaceutical myth therefore promotes that:

\section{Pharmaceutical Myth}

A cure is imminent.

In December 2014, the G8—France, Germany, Italy, Japan, United Kingdom, United States, Canada and Russia-stated that dementia should be made a global priority with the aim of a cure or treatment by 2025 [38]. After one hundred years of consistent failures such an aspirational goal, by the richest countries in the world, exposes hubris and political expediency rather than scientific goals. The reality is more sobering. In January 2018 Pfizer, the world's third largest drug maker, announced that it is ending research aimed at discovering new medications for Alzheimer's disease, a move that most other large pharmaceutical companies will probably follow [39]. In the past 20 years, Pfizer has conducted over a hundred clinical trials, testing twenty-four potential Alzheimer's drugs resulting in only one drug, Aricept, being approved. The reality on the ground differs from the high aspirations of political rhetoric.

The latest definition of Alzheimer's disease as promoted by the Framework [6] relying exclusively on biological markers explicitly aims at finding pharmaceutical interventions. This is not surprising since most of the authors and publishers of the Framework have economic interests in the pharmacological industry [40,41]. Such conflicts of interest should have consequences as they have in France [42]. In the United States, conflicts of interest although acknowledged remain absolved of consequences.

The NIA Framework definition is dependent on the amyloid cascade hypothesis [43] where immunization against plaques (amyloid- $\beta 42$ peptide) and now tangles (neuritic tau) was the proposed treatment. So far, all types of immunization trials for both plaques and tangles continue to fail. The active amyloid immunization clinical trial by Elan Pharmaceuticals (AN1792) indicated that plaques can be cleared from the brain without improved cognition even after long-term follow-up [44-47]. This suggests that the plaques cannot be causing the disease [48] and that something else must be operant. The Framework now argues 
that the amyloids are precursors to the real disease-tau tangles. An argument made a century ago by Oskar Fischer [26]. But this strategy adopts the same assumptions as for the amyloid hypothesis [49] and so far, the results have been predictably insignificant and diffuse $[50,51]$.

With the new target to develop a cure for Alzheimer's disease by 2025 [52] we continue to ignore our "...incomplete understanding of AD pathogenesis, the multifactorial etiology and complex pathophysiology of the disease, the slowly progressive nature of $\mathrm{AD}$, and the high level of comorbidity occurring in the elderly population."[53]. To paraphrase Arnold Pick more than a century ago; "a mosaic of circumscribed neuropsychological deficits" can cause dementia [54], there are many events that can contribute to Alzheimer's disease. This mosaic likely includes [15]: viral (HIV/AIDS, herpes simplex virus type I, varicella zoster virus, cytomegalovirus, Epstein-Barr virus), bacteria (syphilis and lyme-disease/borrelia), parasites (toxoplasmosis, cryptococcosis and neurocysticercosis), fungi (Candida collaborator), infections (possibly prions, DTP-43), and vascular (stroke, multiple-infarct dementia, hydrocephalus, injury and brain tumors)[15]. There are other processes that either promote or delay the infection and the spread of infection, primarily through the Blood-Brain-Barrier [55], inflammation, vascular, White Matter [56] and many other dynamic processes in the brain. Such models already exist [57]. The approach promoted by the NIA through the Framework explicitly ignores these in favor of developing a pharmacological intervention and in so doing creates a myth.

Alternatively, scientists have had more success with interventions that delay the disease. The brain protects itself from getting infected, and once infected has methods to cope with the infection. Protective factors include cognitive reserve and the capacity of the brain to absorb trauma (education, multilingual, exercise, diet, enriched environment in infancy.) While factors that worsen resilience includes: behavior (alcohol, cigarette smoking, recreational drugs, concussion), environmental elements (possibly aluminum), and emotional trauma (divorce, death of a loved one, sexual, physical and emotional abuse and depression) [15]. There are also cascading effects where one infection destroys or diminishes the ability of another system to protect the brain. For example both amyloids and tangles diminish the blood-brain barrier and thereby exposing the brain to outside infections [5860].

Such complexity does not bode well within myths of simple interventions or simple definitions. At best drugs have remained ineffective, at worse they have made things worse. Sometimes people living with dementia on medication die earlier than those who delay or do not go on medication [61]. People with dementia who had consulted a specialist at the start of their disease died earlier than those who (equally) only saw their primary care physician or did nothing [61]. Such a conclusion was predicted by a 2014 study by two Dartmouth professors Steven Woloshin and Lisa Schwartz [62] who found that there was not one Alzheimer's disease drug they could recommend because they were ineffective, expensive and most had severe side-effects. Despite these annual Consumer Reports, half of nursing home residents with dementia are still getting questionable medication in their last years of life [63-65]. In addition to the lack of positive clinical outcomes there is no evidence that any drug has ever improved the quality of life for people living with dementia [66]. Although there are pragmatic reasons why clinicians administer medication with doubtful efficacy, however in research such practices are less valid. There is a lack of science in this field, honoring the credo to try anything that might work while relegating science to the background. But without science it is unlikely that we can ever develop a cure.

\section{Statistical Myth}

Nowadays Alzheimer's disease and late-onset (senile) dementia are considered to be one and the same disease. Initially, Alois Alzheimer defined the disease that took his name as different from senile dementia because the beta amyloids (plaques) and the neuritic tau (tangles) affected young patients. The blending of Alzheimer's disease with senile dementia came from Robert Katzman, one of the founders of the NIA, in an effort to try to gain support for the establishment of the NIA in the 1970s [67]. Katzman wrote that there were so few patients suffering from Alzheimer's disease no record exists; "Precise epidemiological information [on Alzheimer's disease] is not available..." [67]. It was becoming apparent that most patients with senile dementiaonset of disease after 65 years-have very similar brain pathology as patients with Alzheimer's disease [68]. Because it was politically expedient, dementia and Alzheimer's disease were argued to be the same disease contradicting Alois Alzheimer's initial observation [69]. However, because the establishment of the NIA relied in part, on having Katzman's "killer" disease affect a large population, membership was radically broadened to include senile dementia as part of Alzheimer's disease[67,70,71]. This decision was political rather than scientific, suddenly transforming Alzheimer's disease into the fourth or fifth most common cause of death in the United States. Overnight Alzheimer's disease "became" a national public health issue. Just as Emil Kraepelin "created" Alzheimer's disease, Robert Katzman "transformed" it into a public health menace. As a result, the statistical myth goes something like the following:

\section{Statistical Myth}

The older you become the more likely that you will get Alzheimer's disease.

Not surprisingly, simply by broadening the definition of Alzheimer's disease to include late-onset (senile) dementia results in increase prevalence of the disease with age. This expansion also seems likely to capture other diseases in the definition as well. Alzheimer's disease has become such a broad clinical category that most terminal diseases (e.g., hypertension, atherosclerosis, arteriosclerosis, and a host of vascular diseases) contribute to the development of Alzheimer's disease as well [23]. Alzheimer's disease in isolation from these other chronic diseases is rare, and 
among older adults unlikely [72]. Most chronic diseases contribute to the development of Alzheimer's disease, which is why it remains difficult, and in some cases impossible to separate cause of death among older adults [73].

Alzheimer's disease among older adults might have outwardly similar clinical expressions but neurological mechanisms can be very different because there are so many other co-morbidities present. For example, it is rare for older adults to have brain disease in isolation from other type of (non-cognitive) diseases such as depression [74] and anxiety [75]. Since individuals have multiple comorbidities, isolating the disease includes both a clinical as well as a neurological problem [76]. As a result, many dementias are misdiagnosed [77-79]. This helps explain why multiple studies have shown that the correlation between plaques and tangles and Alzheimer's disease declines with age [80].

The estimated risk of getting dementia for a 65-year-old woman is $19 \%$, comparable with the $16 \%$ for hip fracture [81] and $23 \%$ of developing cancer [82]. In men, the lifetime risk of dementia is $11 \%$ twice the $6 \%$ risk of a hip fracture [83] but a third of the risk at $29 \%$ for cancer [82]. As a result, for those over 80 years of age other causes of death rise so rapidly that dementia becomes less of a problem [84]. So that lifetime risk of contracting Alzheimer's disease at the age of 85 years is marginally lower than it was at age 65 years, other diseases gain prominence in older ages. The increase in Alzheimer's disease is due to the increase in the aging population. The same logic applies to why the rate of dementia is higher for women. The likelihood of dementia is approximately twice as high in women (19\%) than in men (11\%) reflecting the longer life expectancy of women [84].

Primarily for clinical ease [85] as well as for policy reasons [67] lumping senile dementia and Alzheimer's disease under one broad category caused confusion in research. Everything that affects memory, behavior, and coping with daily life becomes categorized under this generic disease. A disease that ostensibly has a specific neurological cause that science does not support. In its true clinical form, as defined by Alois Alzheimer, the disease remains extremely rare. But under the new more generic definition, Alzheimer's disease increases with age because of a concomitant increase of clinically-related neurological, biological as well as emotional and psychological issues [86]. Alzheimer's disease are related more to aging than to a specific disease. Science supports this assertion. The apolipoprotein epsilon gene that is strongly associated with lateonset Alzheimer's disease is also the main gene correlated with long life (especially epsilon 2 and 3) [87]. In addition plaques and tangles have been reported to have a positive role in the brain by imprisoning bacterial pathogens and it remains unclear whether plaques are fighting a real or falsely perceived infection [88]. Even prion that causes Gerstmann-Sträussler syndrome and CreutzfeldtJakob disease [89] has a positive role when it comes to neurogenesis where prions facilitate the growth of new neurons in human brains [90]. Some genes might also have different functions at different ages [91]. Alzheimer's disease has become an umbrella term for many other diseases associated with aging. The mechanism for these diseases might also have positive roles in our brain. By simplifying these neurological complexity the myth of Alzheimer's disease has morphed to represent the fear of aging in general.

\section{Caregiver Myth}

The fear of dementia is growing. This fear indicates not only lack of knowledge about the disease but also its perceived burden. In 2010 the fear of dementia rose from the second most feared disease [92] to the most feared disease in 2011[93]. Fear of dementia is so strong that a new term has evolved to describe it: "Dementiaphobia". These are well-founded fears that cannot easily be discounted. As a result, most caregivers' initial response to the diagnosis is for a "cure" to make the problem go away. This is not helped by the publicity from the Alzheimer's Association and pharmacological industry that entices donors by a "cure around the corner" slogan, nor is the myth helpful that claims medication can "slow the disease." For caregivers the myth is that dementia can be cured:

\section{Caregiver Myth}

Alzheimer's disease is a tragedy. The only solution is to find a cure.

Contrary to popular belief, quality of life for people with dementia does not necessarily decrease as dementia progresses [94-96]. Although outcomes vary and are inconsistent, the general trend is that at three months following admission to a long-term care facility only those with better cognitive abilities reported a decrease in their quality of life [97]. People with dementia living at home show more depressive symptoms compared to those living in long-term care facilities. In fact, depression is reduced after entering a long-term care facility [98], which may reflect the negative interpersonal dynamics at home [99]. Tom Kitwood appreciated that some deterioration seen in people with dementia was caused by how the person is treated rather than solely by the disease itself. He called this "malignant social psychology" where a caregiver's relationship, in some extreme cases, devalue, dehumanizes and diminishes the person with dementia [99]. This loss of personhood is brought about by being stigmatized, infantilized, objectified or ignored. Alzheimer's disease is rarely experienced alone or in isolation from a social context. This interpersonal dynamic is an important component of life for people living with dementia. In a 2014 longitudinal study over a 20-month period one-third of people living with dementia rated their quality of life higher [100] determined by the quality of their relationship with a caregiver. Lower quality of life was related to taking acetylcholinesteraseinhibiting medication [100].

There exists a disparity between self-rating of one's quality of life compared to what their caregivers perceive. After 18 months in a care facility, caregivers rated quality of life for the person's living with dementia as lower [96]. Caregivers base their judgment on the patient's functional decline, but for people living with dementia it was anxiety that reduced their quality of life [96]. In most cases, 
anxiety is created by unreachable expectations by their caregivers. As a result of being away from their caregivers, people living with dementia expressed reduced anxiety and better quality of life [96].

There is much complexity in social contexts as quality of life for people living with with dementia varies by country and personal context [97]. For those living in nursing homes, depression lowered their quality of life whereas for those living at home, falls reduced their quality of life [97]. There are many confounding factors, but the evidence is consistent. A year after receiving the devastating diagnosis of dementia, most patients revert to their previous level of wellbeing. Although quality of life is rarely measured in dementia research [101]-more frequently measured during psychosocial interventions rather than during pharmacological studies-when it is reported, any social interaction improves wellbeing among people living with dementia [102]. Gains that are significantly missing (or negative) in pharmacological studies [102].

It is caregivers that suffer the greatest loss of reported quality of life, both in terms of their interaction with the patient and their own health and wellbeing. Caregivers expressed a great amount of psychological distress, including: depression, anxiety, interpersonal sensitivity and paranoid ideation and difficulty with cognitive performance [103]. When compared with spouses who were caring for a spouse without dementia, caregivers of a spouse with dementia had higher psychological distress [104]. Caregivers primarily experience the dementia tragedy, while the quality of interaction with their care receiver determines the quality of life of both [104].

\section{Cultural Myth}

Because Alzheimer's disease evades cure, care remains the only option. Unlike a binary cure, care is more analogue, complex, cultural, messy and social. Caring for someone with dementia is fraught with anxiety, and there is a considerable pursuit for ways to reduce the patient's challenging behaviors $[105,106]$. Before the overpowering scientific myth of dementia, people held-and still hold-different myths of mental illnesses. These myths vary across the world, but there are commonalities.

The most positive and pervasive belief about frail older people is the Confucian concept of Filial Piety which is taught early in life in Asia [107]. People learn that becoming an adult means becoming responsible for others [108]. Despite this expectation, in Japan, the term for dementia is 'chi ho', which translates as a 'disease of cognition associated with idiocy.' Efforts to change it to a less demeaning term have failed because the researchers misunderstood the utility of making dementia sound scary in order to drum-up support for funds to search for a cure [109]. A better approach would be to understand the cultural underpinnings of the term rather than trying to change the culture.

One interpretation is that older adults experiencing dementia are thought to be entering into the spirit world. Although there is great heterogeneity of interpretations, a supernatural interpretation can take either a positive slant (communication with the spirits) or a negative slant (bad karma for past misdeeds). In Guangzhou, China, old age is venerated as having an abundance of life force that can be transmitted by touch and proximity [108]. In this context, old age overlays the negative aspects of dementia [110]. Similarly, in West Bengal, India there is an expectation that older adults detach from society [111]. In Hindu religion this detachment signifies a readiness to offer oneself up to die and then be burned on a funeral pyre. Such supernatural interpretations, both positive and negative, explain dementia as preordained, allowing for the normalization of demented behaviors and diminishing the anxiety for the caregivers [111]. A similar supernatural interpretation of dementia exists among Choctaw Nation, in an isolated part of Oklahoma where people with dementia are believed to be communicating with "the other side" - the side inhabited by the spirits of the dead [112]. Especially when recent memory becomes compromised and long dead relatives are believed to be still alive [112]. Such spiritual interpretation provides caregivers a reason to allow the person to be who they are, rather than who they were before they had dementia-and thereby eliminating Kitwood's malignant social psychology. Accepting the disease is the antithesis of "finding a cure" myth. As such, by allowing people with dementia to be themself, these indigenous groups are honoring Tom Kitwood's prescription for personhood. Viewing demented behaviors not only as normal but supernormal, diminishes caregivers' anxiety. This is true even when myths are negative, as in the Polynesian island of Niue where people suffering from dementia are accused of being possessed by evil spirits [113]. Or when dementia is seen as a normal part of aging as is the case in India [114] and among Vietnamese immigrants to the USA [115], they normalize the behaviors associated with dementia and provide a narrative that diminish the anxiety surrounding it. Such supernatural myths can be both positive and negative, as follows:

\section{Supernatural Myths}

Among older adults close to death, dementia indicates that they are communicating with the spirits of dead people.

\section{Alternative}

Dementia is a punishment from the spirits that cannot be undone.

Cultural myths help caregivers normalize errant behaviors by people living with dementia as pre-ordained and pre-destined across the world [116-119]. In contrast, stigma associated with dementia may exacerbate stress by generating disgrace and shame [120]. Supernatural interpretation allows for the stigma to be diminished.

\section{Creating a new Mythology (Mythopoeia)}

Summarizing research on dementia remains elusive because there is so much of it, across so many technical disciplines. A 2017 review concludes that "...around $35 \%$ of dementia is attributable to a combination of these nine risk factors; early education up to age 11 or 12 , hypertension, obesity, hearing loss and laterlife depression, diabetes, physical inactivity, smoking and social 
isolation" [121]. There is a resistance to acknowledging that what will truly delay dementia and Alzheimer's disease is preventive care and lifestyle choices. There is no panacea. Even people living with dementia and their caregivers have started questioning these myths about the disease [122]. Alzheimer's disease has come to epitomize the sum of illness, aging, and dying [123]. Overcoming this fear can only come from those who confront it. There is a new wave of patient advocacy in dementia [124] promoted by emerging researchers [125-129] based on disability advocacy movements and people living with dementia.

A person living with dementia refers to the disease as "biological war" and "the holocaust of my brain" [130] while others consider it as a possitve: "I wasn't crazy. I wasn't stupid. I could quit trying so hard to cover up my forgetfulness." [131]. Such comments point to the diversity of experience in people with dementia. The banner for this movement is best exemplified by the Australian Christine Bryden's title "Nothing about us, without us." [132]. Such advocacy work builds upon the foundation established by disability advocacy work. This new narrative-a modern example of Mythopoeia-emerges organically from narratives of people living with dementia. These accounts stress the importance of reasserting one's capabilities, allowing the person to struggle to re-learn or retain as much as they can before they forget. When all alternatives have been exhausted, eventually the disease can become an opportunity. By accepting the disease we can help someone as they need to be helped. Family members and friends are seen as companions rather than as caregivers. We don't call mothers or fathers "caregivers" even though that is what they do. We elevate their role. We need to elevate caregiving to "companion or care partner" [132]. Kitwood saw that people living with dementia are not only disadvantaged by the disease itself but also by the attitudes and actions of those around. Through Person-Centered Therapy [99] individuals dictate what is best for them. But this was not enough. In Personhood although the individual has rights, those rights are rarely enforced, to do this a new concept of Citizenship has emerged where individuals have rights that are enforced [133]. Citizenship assumes that individuals have the capacity to exercise those rights, not obvious among people with severe dementia. To get around this conundrum, the concept of 'Intimate Citizenship' has been put forward, that focuses on citizenship moderated and mediated by companions including clinicians. But Intimate Citizenship can also be flawed. One study reports that "It is not policy or legislation but clinicians' personal values that resulted in people with dementia having the most restrictive care outcomes" [134]. Even when people living with dementia overcome this and start to advocate on their behalf, activists reported oppression related to how they are expected to behave [135]. People with dementia still have a story to tell [136] and they might influence the stories of those who interact with them. "Presently there is a lack of both an authoritative framework for thinking about legal competence and clear standards for determining it."[137] There is a movement in our culture striving to re-imagine the person with dementia condensed from the autobiographies of people living with dementia [138-160].

\section{New Myth}

For now, this cannot be cured. This is going to take me on a different journey than the one I wanted. I have no control how I will change. I need companions to share this journey. There are lessons for you and me in this and we will both need help. Accept me as I am today, not as I used to be. Love me as I need to be loved. Every loss defines our shared humanity. I will remain human and therefore feel.

\section{Acknowledgement}

None.

\section{Conflict of Interest}

No conflict of interest.

\section{References}

1. Kaiser J (2018) The Alzheimer's gamble. Science 361(6405): 838-841.

2. Mitchell SL, Teno JM, Kiely DK, Shaffer ML, Jones RN, et al. (2009) The clinical course of advanced dementia. New England Journal of Medicine 361(16):1529-38.

3. McInerney F, Doherty K, Bindoff A, Robinson A, Vickers J (2018) How is palliative care understood in the context of dementia? Results from a massive open online course. Palliative medicine 32(3): 594-602.

4. Khalil RB, Khoury E, Koussa S (2016) Linking multiple pathogenic pathways in Alzheimer's disease. World journal of psychiatry 6(2): 208214.

5. Garrett MD (2018) A Critique of the 2018 National Institute on Aging's. Research Framework: Toward a biological definition ofAlzheimer's disease. Curr Neurobiol 9(1): 49-58

6. Jack Jr CR, Bennett DA, Blennow K, Carrillo MC, Dunn B, et al. (2018) NIAAA Research Framework: Toward a biological definition of Alzheimer's disease. Alzheimer's \& Dementia 14(4): 535-562.

7. Jack Jr CR, Albert MS, Knopman DS, McKhann GM, Sperling RA, et al. (2011) Introduction to the recommendations from the National Institute on Aging-Alzheimer's Association workgroups on diagnostic guidelines for Alzheimer's disease. Alzheimer's \& Dementia 7(3): 257-262.

8. Allchin D (2003) Scientific myth_conceptions. Science education 87(3): 329-51.

9. Hinton L, Guo Z, Hillygus J, Levkoff S (2000) Working with culture: A qualitative analysis of barriers to the recruitment of Chinese-American family caregivers for dementia research. Journal of cross-cultural gerontology 15(2): 119-137.

10. Sismondo S (1996) Science without myth: On constructions, reality, and social knowledge. SUNY Press, USA.

11. Maccormac ER (1978) Metaphor and myth in science and religion. Philosophical Review 87(2): 299.

12. Singer I (2008) Cinematic Mythmaking. Philosophy in Film.

13. Whitehouse PJ (2014) The end of Alzheimer's disease-From biochemical pharmacology to ecopsychosociology: A personal perspective. Biochemical pharmacology 88(4): 677-681.

14. The LN (2016) Finding a cure for Alzheimer's disease starts with prevention. The Lancet. Neurology 15(7): 649.

15. Garrett MD, Valle R (2015) A New Public Health Paradigm for Alzheimer's Disease Research. SOJ Neurol 2(1): 1-9.

16. Ballenger JF (2017) Framing confusion: Dementia, society, and history. AMA journal of ethics 19(7): 713-719. 
17. Garrett MD, Valle R (2016) A century of confusion in researching Alzheimer's disease. Int J Healthcare 2: 13.

18. Whitehouse PJ, George D (2008) The myth of Alzheimer's: What you aren't being told about today's most dreaded diagnosis. Macmillan.

19. Weuve J, Proust-Lima C, Power MC, Gross AL, Hofer SM, et al. (2015) Guidelines for reporting methodological challenges and evaluating potential bias in dementia research. Alzheimer's \& Dementia 11(9):1098-1109.

20. Jessen F, Amariglio RE, Van Boxtel M, Breteler M, Ceccaldi M, et al. (2014) A conceptual framework for research on subjective cognitive decline in preclinical Alzheimer's disease. Alzheimer's \& Dementia 10(6): 844852.

21. Bennett DA, Yu L, Yang J, Klein HU, De Jager PL (2017) Epigenomics of Alzheimer's disease. In Translating Epigenetics to the Clinic, Academic Press, USA, pp. 227-278.

22. Au R, Piers RJ, Lancashire L (2015) Back to the future: Alzheimer's disease heterogeneity revisited. Alzheimer's \& Dementia: Diagnosis. Assessment \& Disease Monitoring 1(3): 368.

23. Snyder HM, Corriveau RA, Craft S, Faber JE, Greenberg SM, et al. (2015) Vascular contributions to cognitive impairment and dementia including Alzheimer's disease. Alzheimer's \& Dementia 11(6): 710-717.

24. Garrett MD, Valle R (2016) A methodological critique of the National Institute of Aging and Alzheimer's Association Guidelines for Alzheimer's disease, dementia, and mild cognitive impairments. Dementia 15(2): 239-254.

25. Goedert M, Ghetti B (2007) Alois Alzheimer: his life and times. Brain pathology 17(1): 57-62.

26. Goedert M (2008) Oskar Fischer and the study of dementia. Brain 132(4): 1102-1111.

27. Garrett MD (2015) Politics of Anguish: How Alzheimer's Disease Became the Malady of the 21st Century. Createspace.

28. Fox P (1989) From senility to Alzheimer's disease: The rise of the Alzheimer's disease movement. The Milbank Quarterly 1: 58-102.

29. Manton KG, Patrick CH, Stallard E (1980) Mortality model based on delays in progression of chronic diseases: alternative to cause elimination model. Public Health Reports 95(6): 580-588.

30. Manuel DG, Leung M, Nguyen K, Tanuseputro P, Johansen H (2003) Burden of cardiovascular disease in Canada. Canadian Journal of Cardiology 19(9): 997-1004.

31. Manuel DG, Schultz SE, Kopec JA (2002) Measuring the health burden of chronic disease and injury using health adjusted life expectancy and the Health Utilities Index. Journal of Epidemiology \& Community Health 56(11): 843-850.

32. Port FK (1995) End-stage renal disease: Magnitude of the problem, prognosis of future trends and possible solutions. Kidney International Supplement 2(50): S3-S6.

33. Kane MN (2002) Awareness of ageism, motivation, and countertransference in the care of elders with Alzheimer's disease. American Journal of Alzheimer's Disease \& Other Dementias® 17(2): 101-119.

34. Brookes G, Harvey K, Chadborn N, Dening T (2018) "Our biggest killer": multimodal discourse representations of dementia in the British press. Social Semiotics 28(3): 371-395.

35. Ashburn TT, Thor KB (2004) Drug repositioning: identifying and developing new uses for existing drugs. Nature reviews Drug discovery 3(8): 673.

36. Dovrolis N, Kolios G, Spyrou G, Maroulakou I (2017) Laying in silico pipelines for drug repositioning: a paradigm in ensemble analysis for neurodegenerative diseases. Drug discovery today 22(5): 805-813.

37. Hakala AK, Fergusson D, Kimmelman J (2017) Nonpublication of trial results for new neurological drugs: a systematic review. Annals of neurology 81(6): 782-789.
38. Vradenburg G (2015) A pivotal moment in Alzheimer's disease and dementia: how global unity of purpose and action can beat the disease by 2025. Expert review of neurotherapeutics 15(1): 73-82.

39. Rinaldi A (2018) Setbacks and promises for drugs against Alzheimer's disease: As pharmaceutical companies are retreating from drug development for Alzheimer's, new approaches are being tested in academia and biotech companies. EMBO reports 19(9): e46714.

40. Garrett MD (2018) The argument against crowdfunding Alzheimer's disease research. Advances in Health and Behavior 1(1): 49-61.

41. Yasgur BS (2018) Radical New Definition of Alzheimer's Relies on Biomarkers. Medscape. Accessed online:

https://www.medscape.com/viewarticle/895057

42. Lenzer J (2011) French guidelines are withdrawn after court finds potential bias among authors. BMJ 342: d4007

43. Hardy JA, Higgins GA (1992) Alzheimer's disease: the amyloid cascade hypothesis. Science 256(5054): 184.

44. Hock C, Konietzko U, Streffer JR, Tracy J, Signorell A, et al. (2003) Antibodies against _-amyloid slow cognitive decline in Alzheimer's disease. Neuron 38(4): 547-554.

45. Bayer AJ, Bullock R, Jones RW, Wilkinson D, Paterson KR, et al. (2005) Evaluation of the safety and immunogenicity of synthetic A_42 (AN1792) in patients with AD. Neurology 64(1): 94-101.

46. Gilman S, Koller M, Black RS, Jenkins L, Griffith SG, et al. (2005) Clinical effects of a immunization (AN1792) in patients with AD in an interrupted trial. Neurology 64(9): 1553-1562.

47. Holmes C, Boche D, Wilkinson D, Yadegarfar G, Hopkins V, et al. (2008) Long-term effects of A_42 immunisation in Alzheimer's disease: follow-up of a randomised, placebo-controlled phase I trial. The Lancet 372(9634): 216-223.

48. Iqbal K, Liu F, Gong CX (2014) Alzheimer disease therapeutics: focus on the disease and not just plaques and tangles. Biochemical pharmacology 88(4): 631-639.

49. Cappa SF (2018) The quest for an Alzheimer therapy. Frontiers in neurology 9: 108.

50. Boche D, Donald J, Love S, Harris S, Neal JW, Holmes C, Nicoll JA (2010) Reduction of aggregated Tau in neuronal processes but not in the cell bodies after A_42 immunisation in Alzheimer's disease. Acta neuropathologica 120(1): 13-20.

51. Li X, Kaida-Yip F, Zabel M (2018) NSAID Use and the Prevention of Alzheimer's Disease: A Meta-Analysis (P6. 184).

52. Cummings J, Aisen PS, DuBois B, Frölich L, Jack CR, et al. (2016) Drug development in Alzheimer's disease: the path to 2025. Alzheimer's research \& therapy 8(1): 39.

53. Sugino H, Watanabe A, Amada N, Yamamoto M, Ohgi Y, et al. (2015) Global trends in Alzheimer disease clinical development: increasing the probability of success. Clinical therapeutics 37(8): 1632-1642.

54. Spatt J (2003) Arnold Pick's concept of dementia. Cortex 39(3): 525-531.

55. Deane R, Bell RD, Sagare A, Zlokovic BV (2009) Clearance of amyloid_ peptide across the blood-brain barrier: implication for therapies in Alzheimer's disease. CNS \& Neurological Disorders-Drug Targets (Formerly Current Drug Targets-CNS \& Neurological Disorders) 8(1): 16-30.

56. Serrano-Pozo A, Mielke ML, Gómez-Isla T, Betensky RA, Growdon JH, et al. (2011) Reactive glia not only associates with plaques but also parallels tangles in Alzheimer's disease. The American journal of pathology 179(3): 1373-1384.

57. Schelke MW, Attia P, Palenchar D, Kaplan B, Mureb M, et al. (2018) Mechanisms of risk reduction in the clinical practice of Alzheimer's disease prevention. Frontiers in aging neuroscience 10: 96.

58. Bell RD, Zlokovic BV (2009) Neurovascular mechanisms and blood-brain barrier disorder in Alzheimer's disease. Acta neuropathologica 118(1): 103-113. 
59. Shibata M, Yamada S, Kumar SR, Calero M, Bading J, et al. (2000) Clearance of Alzheimer's amyloid-_ 1-40 peptide from brain by LDL receptor-related protein-1 at the blood-brain barrier. The Journal of clinical investigation 106(12): 1489-1499.

60. Zenaro E, Piacentino G, Constantin G (2017) The blood-brain barrier in Alzheimer's disease. Neurobiology of disease 107: 41-56.

61. Pimouguet C, Delva F, Le Goff M, Stern Y, Pasquier F, et al. (2015) Survival and early recourse to care for dementia: a population based study. Alzheimer's \& Dementia 11(4): 385-393.

62. Consumer Reports (2018) The hard truth about Alzheimer's drugs: Aricept, Exelon, and Razadyne do little to help most people and pose risks 2014.

63. Matlow JN, Bronskill SE, Gruneir A, Bell CM, Stall NM, et al. (2017) Use of medications of questionable benefit at the end of life in nursing home residents with advanced dementia. Journal of the American Geriatrics Society 65(7): 1535-1542.

64. Rochon PA, Normand SL, Gomes T, Gill SS, Anderson GM, et al. (2008) Antipsychotic therapy and short-term serious events in older adults with dementia. Archives of internal medicine 168(10): 1090-1096.

65. Green AR, Reifler LM, Boyd CM, Weffald LA, Bayliss EA (2018) Medication profiles of patients with cognitive impairment and high anticholinergic burden. Drugs \& aging 35(3): 223-232.

66. Cooper C, Mukadam N, Katona C, Lyketsos CG, Blazer D, et al. (2013) Systematic review of the effectiveness of pharmacologic interventions to improve quality of life and well-being in people with dementia. The American Journal of Geriatric Psychiatry 21(2): 173-183.

67. Katzman R (1976) The prevalence and malignancy of Alzheimer disease: a major killer. Archives of neurology 33(4): 217-218.

68. Ballenger JF (2006) Self, senility, and Alzheimer's disease in modern America: A history. JHU Press, USA.

69. Robertson A (1990) The politics of Alzheimer's disease: A case study in apocalyptic demography. International Journal of Health Services 20(3): 429-442.

70. Katzman R, Karasu T (1975) Differential Diagnosis of Dementia. In Neurological and Sensory Disorders in the Elderly, ed. W. Fields, New York: Stratton Intercontinental Medical Book Corp, USA, pp. 103-134.

71. Katzman R, Bick K (2000) Alzheimer Disease: The Changing View: The Changing View. Elsevier.

72. Sanderson M, Wang J, Davis DR, Lane MJ, Cornman CB, et al. (2002) Comorbidity associated with dementia. American Journal of Alzheimer's Disease \& Other Dementias® 17(2): 73-78.

73. Nuland SB (2002) How we die: Reflections on life's final chapter. Vintage 17(2): 73-78.

74. Wagner GS, McClintock SM, Rosenquist PB, McCall WV (2011) Major depressive disorder with psychotic features may lead to misdiagnosis of dementia: a case report and review of the literature. Journal of psychiatric practice 17(6): 432-438.

75. Guziak CC, Smith JE (2014) Anxiety Misdiagnosed as Dementia? A Complex Case Successfully Treated Using a Multimodal Biofeedback Approach. Biofeedback 42(1): 12-15.

76. Qiu C, De Ronchi D, Fratiglioni L (2007) The epidemiology of the dementias: an update. Current opinion in psychiatry 20(4): 380-385.

77. Nielsen TR, Andersen BB, Kastrup M, Phung TK, Waldemar G (2011) Quality of dementia diagnostic evaluation for ethnic minority patients: a nationwide study. Dementia and geriatric cognitive disorders 31(5): 388-396.

78. Sayegh P, Knight BG (2013) Assessment and diagnosis of dementia in Hispanic and non-Hispanic White outpatients. The Gerontologist 53(5): 760-769.

79. Savva GM, Wharton SB, Ince PG, Forster G, Matthews FE, et al. (2009) Age, neuropathology, and dementia. New England Journal of Medicine 360(22): 2302-2309.
80. Black DM, Cummings SR, Melton III LJ (1992) Appendicular bone mineral and a woman's lifetime risk of hip fracture. Journal of Bone and Mineral Research 7(6): 639-646.

81. Black S, Simpson GM (2014) A Call to Action: Dementia Screening of Alzheimer's Disease in Older African Americans. In The collective spirit of aging across cultures, Springer, Dordrecht, pp. 229-238.

82. Brenner H, Stegmaier C, Ziegler H (1990) Magnitude and time trends of the life-time risk of developing cancer in Saarland, Germany. European Journal of Cancer and Clinical Oncology 26(9): 978-982.

83. Lauritzen JB, Schwarz P, Lund B, McNair P, Transbøl I (1993) Changing incidence and residual lifetime risk of common osteoporosis-related fractures. Osteoporosis international 3(3): 127-132.

84. Seshadri S, Wolf PA, Beiser A, Au R, McNulty K, White R, D'agostino RB (1997) Lifetime risk of dementia and Alzheimer's disease: The impact of mortality on risk estimates in the Framingham Study. Neurology 49(6): 1498-504.

85. Kalaria R (2002) Similarities between Alzheimer's disease and vascular dementia. Journal of the Neurological Sciences 203: 29-34.

86. Nelson PT, Head E, Schmitt FA, Davis PR, Neltner JH, et al. (2011) Alzheimer's disease is not "brain aging": neuropathological, genetic, and epidemiological human studies. Acta neuropathologica 121(5): 571587.

87. Ferri E, Gussago C, Casati M, Mari D, Rossi PD, et al. (2019) Apolipoprotein E gene in physiological and pathological aging. Mechanisms of ageing and development 178: 41-45.

88. Kumar DK, Choi SH, Washicosky KJ, Eimer WA, Tucker S, et al. (2016) Amyloid- $\beta$ peptide protects against microbial infection in mouse and worm models of Alzheimer's disease. Science translational medicine 8(340): 340ra72.

89. Serban D, Taraboulos A, DeArmond SI, Prusiner SB (1990) Rapid detection of Creutzfeldt_Jakob disease and scrapie prion proteins. Neurology 40(1): 110-117.

90. Steele AD, Emsley JG, Özdinler PH, Lindquist S, Macklis JD (2006) Prion protein $(\mathrm{PrPc})$ positively regulates neural precursor proliferation during developmental and adult mammalian neurogenesis. Proceedings of the National Academy of Sciences 103(9): 3416-3421.

91. Capri M, Salvioli S, Sevini F, Valensin S, Celani L, et al. (2006) The genetics of human longevity. Annals of the New York Academy of Sciences 1067(1): 252-263.

92. MetLife Foundation (2011) What America thinks. The MetLife Foundation Alzheimer's survey, New York, USA.

93. MIPO-Marist Institute for Public Opinion (2012) Alzheimer's most feared disease survey for Home Instead Senior Care.. Accessed: http:// www.helpforalzheimersfamilies.com/alzheimers-dementia-careservices/alzheimers_feared_disease/

94. Selwood A, Thorgrimsen L, Orrell M (2005) Quality of life in dementia-a one_year follow_up study. International journal of geriatric psychiatry 20(3): 232-237.

95. Hoe J, Hancock G, Livingston G, Woods B, Challis D, et al. (2009) Changes in the quality of life of people with dementia living in care homes. Alzheimer Disease and associated disorders 23(3): 285-290.

96. Bosboom PR, Alfonso H, Almeida OP (2013) Determining the predictors of change in quality of life self-ratings and carer-ratings for communitydwelling people with Alzheimer disease. Alzheimer Disease \& Associated Disorders 27(4): 363-371.

97. Beerens HC, Zwakhalen SM, Verbeek H, Ruwaard D, Ambergen AW, et al. (2015) Change in quality of life of people with dementia recently admitted to long_term care facilities. Journal of Advanced Nursing 71(6): 1435-1447.

98. Payne JL, Sheppard JM, Steinberg M, Warren A, Baker A, et al. (2002) Incidence, prevalence, and outcomes of depression in residents of a long term care facility with dementia. International journal of geriatric psychiatry 17(3): 247-253. 
99. Kitwood T (1998) Toward a theory of dementia care: ethics and interaction.

100. Clare L, Woods RT, Nelis SM, Martyr A, Markova IS, et al. (2014) Trajectories of quality of life in early_stage dementia: individual variations and predictors of change. International Journal of Geriatric Psychiatry 29(6): 616-623.

101. Schölzel_Dorenbos CJ, Ettema TP, Bos J, Boelens_van der Knoop E, Gerritsen DL, et al. (2007) Evaluating the outcome of interventions on quality of life in dementia: selection of the appropriate scale. International Journal of Geriatric Psychiatry: A journal of the psychiatry of late life and allied sciences 22(6): 511-519.

102. Cohen-Mansfield J (2004) Nonpharmacologic interventions for inappropriate behaviors in dementia: a review, summary, and critique. Am J Geriatr Psychiatry 9(2): 361-308.

103. Pot AM, Deeg DJ, Van Dyck R (1997) Psychological well-being of informal caregivers of elderly people with dementia: changes over time. Aging \& Mental Health 1(3): 261-268.

104. Ask H, Langballe EM, Holmen J, Selbæk G, Saltvedt I, et al. (2014) Mental health and wellbeing in spouses of persons with dementia: the Nord-Trøndelag health study. BMC Public Health 14(1): 413.

105. Fisher JE, Swingen DN (1997) Contextual factors in the assessment and management of aggression in dementia patients. Cognitive and Behavioral Practice 4(1): 171-190.

106. Moniz_Cook E, Woods RT, Richards K (2001) Functional analysis of challenging behaviour in dementia: the role of superstition. International journal of geriatric psychiatry 16(1): 45-56.

107. Koehn A (1943) Filial devotion in China. Peking: Lotus Court Publications.

108. Ikels C (2002) Constructing and deconstructing the self: Dementia in China. Journal of Cross-Cultural Gerontology 17(3): 233-251.

109. Miyamoto M, George DR, Whitehouse PJ (2011) Government, professional and public efforts in Japan to change the designation of dementia (chiha). Dementia 10(4): 475-486.

110. Dai B, Mao Z, Wu B, Mei YJ, Levkoff S, et al. (2015) Family caregiver's perception of Alzheimer's disease and caregiving in Chinese culture. Social work in public health 30(2): 185-196.

111. Lamb S (2000) White saris and sweet mangoes: Aging, gender, and body in North India.

112. Henderson JN, Henderson LC (2002) Cultural construction of disease: A "supernormal"construct of dementia in an American Indian tribe. Journal of cross-cultural gerontology 17(3): 197-212.

113. Barker JC (1997) Between humans and ghosts: The decrepit elderly in a Polynesian society. The cultural context of aging: Worldwide perspectives 407-424.

114. Cohen L (1992) No aging in India. Ph.D. diss. Ann Arbor: UMI Dissertation Services.

115. Braun KL, Takamura JC, Mougeot T (1996) Perceptions of dementia, caregiving, and help-seeking among recent Vietnamese immigrants. Journal of Cross-Cultural Gerontology 11(3): 213-228.

116. Traphagan JW (1998) Localizing senility: Illness and agency among older Japanese. Journal of Cross-Cultural Gerontology 13(1): 81-98.

117. Traphagan JW (2000) Taming oblivion: Aging bodies and the fear of senility in Japan. SUNY Press, USA.

118. Lanting S, Crossley M, Morgan D, Cammer A (2011) Aboriginal experiences of aging and dementia in a context of sociocultural change: Qualitative analysis of key informant group interviews with Aboriginal seniors. Journal of cross-cultural gerontology 26(1): 103-117.

119. Guo Z, Levy BR, Hinton WL, Weitzman PF, Levkoff SE (2000) The power of labels: recruiting dementia-affected Chinese American elders and their caregivers. Journal of Mental Health and Aging 6(1): 103-112.

120. Sun F, Ong R, Burnette D (2012) The influence of ethnicity and culture on dementia caregiving: A review of empirical studies on
Chinese Americans. American Journal of Alzheimer's Disease \& Other Dementias® 27(1): 13-22.

121. Livingston G, Sommerlad A, Orgeta V, Costafreda SG, Huntley J, et al. (2017) Dementia prevention, intervention, and care. The Lancet 390 (10113): 2673-2734.

122. Neitch MD, Shirley M, Meadows MD, Patton-Tackett MD, Yingling MD, et al. (2016) Dementia care: confronting myths in clinical management.

123. O'rourke N (1996) Alzheimer's disease as a metaphor for contemporary fears of aging. Journal of the American Geriatrics Society 44(2): 220221

124. Hill L, Roberts G, Wildgoose J, Perkins R, Hahn S (2010) Recovery and person-centred care in dementia: common purpose, common practice? Advances in psychiatric treatment 16(4): 288-298.

125. Zimmermann M (2017) About Tradition and Triumph: Patients Popularise Dementia Narrative. In the Poetics and Politics of Alzheimer's Disease Life-Writing, Palgrave Macmillan, Cham, pp. 7594.

126. Zimmermann M (2017) Alzheimer's disease metaphors as mirror and lens to the stigma of dementia. Literature and medicine 35(1): 71-97.

127. Zimmermann M (2017) From a 'Care-Free' Distance: Sons Talking About Cultural Concepts. In the Poetics and Politics of Alzheimer's Disease Life-Writing (pp. 49-73). Palgrave Macmillan, Cham.

128. Zimmermann M (2017) On Reclaiming Authority: The Enabling Discourse of Alzheimer's Disease. In the Poetics and Politics of Alzheimer's Disease Life-Writing Palgrave Macmillan, Cham, pp. 95116.

129. Zimmermann M (2017) The Poetics and Politics of Alzheimer's Disease Life-Writing. Springer.

130. De Baggio T (2002) Losing my mind: An intimate look at life with Alzheimer's. Simon and Schuster.

131. Ballenger JF, Ballenger JF (2006) Self, senility, and Alzheimer's disease in modern America: A history. JHU Press, USA.

132. Bryden C (2015) Nothing about us, without us! 20 years of dementia advocacy. Jessica Kingsley Publishers, USA.

133. Bartlett R, O'Connor D (2007) From personhood to citizenship: Broadening the lens for dementia practice and research. Journal of Aging Studies 21(2): 107-118.

134. Brannelly T (2006) Negotiating ethics in dementia care: an analysis of an ethic of care in practice. Dementia 5(2): 197-212.

135. Bartlett R (2014) Citizenship in action: the lived experiences of citizens with dementia who campaign for social change. Disability \& Society 29(8): 1291-1304.

136. Baldwin C, Group BD (2008) Narrative (,) citizenship and dementia: The personal and the political. Journal of Aging Studies 22(3): 222228.

137. Berg JW, Appelbaum PS, Grisso T (1995) Constructing competence: formulating standards of legal competence to make medical decisions. Rutgers L Rev 48: 345-371.

138. Assauer R (2012) Wie ausgewechselt: verblassende Erinnerungen an mein Leben. Riva Verlag. [Like substituted. Fading memories of my life].

139. Bryden C (2005) Dancing with dementia: My story of living positively with dementia. Jessica Kingsley Publishers, UK.

140. The LN (2016) Finding a cure for Alzheimer's disease starts with prevention. The Lancet. Neurology 15(7): 649.

141. Bryden C (2012) Who will I be when I die? Jessica Kingsley Publishers, USA.

142. Bryden C (2015) Nothing about us, without us! 20 years of dementia advocacy. Jessica Kingsley Publishers, UK.

143. Couturier C (1999) Puzzle: journal d'une Alzheimer. J Lyon. 
144. Davis R, Davis B (1989) My journey into Alzheimer's disease. Wheaton, IL: Tyndale House Publishers, USA.

145. DeBaggio T (2002) Losing my mind: An intimate look at life with Alzheimer's. Simon and Schuster, USA.

146. DeBaggio T (2007) When it gets dark: an enlightened reflection on life with Alzheimer's. Simon and Schuster, USA.

147. Donahue M (2009) From AA to AD. Createspace.

148. Genova L (2014) Still Alice. Simon and Schuster, USA.

149. Graboys TB, Zheutlin P (2008) Life in the balance: a physician's memoir of life, love, and loss with Parkinson's disease and dementia. Union Square Press, USA.

150. Helga Rohra, Aus dem Schatten treten (2011) Warum ich mich für unsere Rechte als Demenzbetroffene einsetze [Stepping out of the shadow. Why I am advocating our rights as those afflicted by dementia] (Frankfurt am Main: Mabuse-Verlag, 2011) (Rohra);

151. Lee JL (2003) Just love me: My life turned upside-down by Alzheimer's. Purdue University Press, USA.

152. McGowin DF (2011) Living in the labyrinth: A personal journey through the maze of Alzheimer's. Delta, USA.
153. Mobley T (2006) I Remember When. Wandering Sage Publications, USA.

154. Mobley T (2007) Young Hope: The Broken Road. Denver: Outskirts Press, USA.

155. Rauschi TM (2001) A View from Within: Living with Early Onset Alzheimer's. Northeastern New York Chapter, Alzheimer's Association.

156. Rohra H (2011) Aus dem Schatten treten. Warum ich mich für unsere Rechte als Demenzbetroffene einsetze. Frankfurt am Main. [Stepping out of the shadow. Why I am advocating our rights as those afflicted by dementia].

157. Rose L (1996) Show me the way to go home. Elder Books, USA.

158. Rose L (2003) Larry's Way: another look at Alzheimer's from the inside. iUniverse, USA.

159. Schneider C (2006) Don't Bury Me--it Ain't Over Yet. Bloomington, IN: AuthorHouse, USA.

160. Taylor R (2006) Alzheimer's from the Inside Out. Health Professions Press, Baltimore, USA.

161. Zimmermann C (2017) Auf dem Weg mit Alzheimer: wie sich mit einer Demenz leben lässt. Mabuse-Verlag. [On the road with Alzheimer's. How it is possible to live with dementia]. 